\title{
CARACTERIZAÇÃO ENERGÉTICA DE DIFERENTES ESPÉCIES DE EUCALYPTUS
}

\author{
Márcia Silva de Jesus ${ }^{1 *}$, Luciano Junqueira Costa $^{1}$, Juliana Ceccato Ferreira ${ }^{1}$, Fabiana Paiva de Freitas ${ }^{1}$, \\ Larissa Carvalho Santos ${ }^{1}$, Maria Fernanda Vieira Rocha ${ }^{1}$ \\ ${ }^{1}$ Universidade Federal de Viçosa, Departamento de Engenharia Florestal, Viçosa, Minas Gerais, Brasil, eng-marcia@ hotmail.com*;
junqueira@ hotmail.com ; cf.juliana @ yahoo.com.br; fabianapf@ hotmail.com; lari.carvalhoufv@gmail.com \\ ${ }^{2}$ Universidade Federal de Lavras, Departamento de Engenharia Florestal, Lavras, Minas Gerais, Brasil, mfvrocha@yahoo.com.br
}

Recebido para publicação: 09/09/2016 - Aceito para publicação: 02/01/2017

\begin{abstract}
Resumo
Objetivou-se realizar a caracterização energética de espécies de eucalipto para a produção de carvão vegetal. As espécies utilizadas foram Eucalyptus grandis x Eucalyptus urophylla, Eucalyptus propinqua, Eucalyptus robusta, Eucalyptus pellita e Eucalyptus botryoides. Avaliou-se o poder calorífico, densidades básica e energética, o rendimento gravimétrico e a análise química imediata do carvão vegetal. O experimento foi conduzido em delineamento inteiramente casualizado, com 3 repetições. A unidade experimental foi a tora, em que coletou-se discos com $5 \mathrm{~cm}$ de espessura, localizados à $0,25,50,75$ e $100 \%$ da altura total da árvore. As carbonizações foram realizadas em forno elétrico com temperatura final de $380{ }^{\circ} \mathrm{C}$. Realizou-se a ANOVA, teste Tukey e correlação segundo Pearson, todos a 5,0\% de probabilidade. O poder calorífico da madeira e o rendimento não se diferiram significativamente entre as espécies em estudo. Os rendimentos médios encontrados foram de 39,65\% em carvão e 21,06\% em gases não condensáveis. O Eucalyptus robusta apresentou características energéticas semelhantes ao híbrido de Eucalyptus grandis x Eucalyptus urophylla, exceto pelas densidades, que naquele foram superiores. A densidade energética da madeira aumentou proporcionalmente à densidade básica, sendo que, a madeira mais densa apresentou maior quantidade de energia disponível. Conclui-se que, as características potenciais (PCS, Db e De) na produção de carvão vegetal foram evidenciadas em todas as espécies, no entanto, o Eucalyptus robusta foi a espécie mais promissora para fins energéticos para ser utilizada como biorredutor.

Palavras-chave: Biomassa; carvão vegetal; Fonte renovável.
\end{abstract}

\begin{abstract}
Energy characterization of different species of Eucalyptus. This study aimed to carry out energy characterization of Eucalyptus species for charcoal production. The species used were Eucalyptus grandis $\mathrm{x}$ Eucalyptus urophylla, Eucalyptus propinqua, Eucalyptus robusta, Eucalyptus pellita and Eucalyptus botryoides. The calorific value, basic and energetic densities, gravimetric yield and the immediate chemical analysis of charcoal were evaluated. The experiment was conducted in a completely randomized design with three replications. The experimental unit was the log, where $5 \mathrm{~cm}$ thick discs were collected at $0,25,50,75$ and $100 \%$ of the total height of the tree. The carbonization were carried out in an electric furnace with a final temperature of $380^{\circ} \mathrm{C}$. Were evaluated the calorific power, basic and energy densities, yields of carbonization and chemical analysis. Were realized ANOVA, Tukey test and Pearson correlation, all at $5.0 \%$ probability. Calorific power of the wood and the carbonization yields did not differ significantly between the species under study. The average yields were $39.65 \%$ in coal and $21.06 \%$ in non-condensable gases. Eucalyptus robusta showed characteristics similar to the hybrid of Eucalyptus grandis x Eucalyptus urophylla, except for densities that were higher in first. The energy density of wood increases with increasing density, denser wood has a higher amount of energy available. It is concluded that the potential characteristics (PCS, Db and De) in charcoal production were evidenced in all species, however, Eucalyptus robusta was the most promising species for energy purposes to be used as a bioreductor.

Keywords: Biomass; charcoal; renewable source.
\end{abstract}

\section{INTRODUÇÃO}

O uso racional de recursos renováveis paralela à redução do consumo de combustíveis fósseis somado à exploração de madeiras oriundas de florestas nativas tem motivado o desenvolvimento de pesquisas, tecnologias e plantios comerciais de espécies com rápido crescimento como Eucalyptus e Pinus.

A biomassa ligno-celulósica é a mais abundante no planeta e pode ser utilizada como matéria-prima para diversos produtos industriais, estimulando uma série de pesquisas biotecnológicas (LU et al., 2008). Trata- 
se uma fonte renovável utilizada como insumo energético de forma primaria ou secundária, por meio de sua transformação em carvão vegetal.

O carvão vegetal como biorredutor tende a apresentar uma baixa densidade energética em relação aos combustíveis fósseis (MÜLLER et al., 2005). Por outro lado, normalmente, o uso de fontes não renováveis para a produção de energia aumenta os teores de enxofre, causador da chuva ácida, e de dióxido de carbono na atmosfera, principal gás do efeito estufa (DI BLASI et al., 2008).

A utilização da madeira como combustível para se obter energia é um processo simples. O rendimento energético da combustão da madeira depende de sua constituição química, variando de espécie para espécie, tornando-se um importante parâmetro de seleção. Segundo a Indústria Brasileira de Árvore (IBÁ) (2015), 15,2\% da área de plantios florestais com Eucalyptus são destinadas à siderurgia e carvão vegetal, sendo o Brasil o maior produtor mundial desse produto, apesar de ainda haver algumas limitações de ordem econômica e técnica na produção dessa biomassa energética (MÜLLER et al., 2005).

A seleção de materiais genéticos superiores, adequados às determinadas condições de sítio, é fundamental para melhor aproveitamento da biomassa como lenha e/ou como biorredutor. Por exemplo, madeiras que apresentam baixo teor de cinzas, elevado teor de lignina e densidade básica proporcionam melhor qualidade e rendimento do carvão vegetal (NEVES et al., 2011; TRUGILHO et al., 2009).

A oferta de contribuições para se ampliar a base de conhecimentos na área da aplicação energética da madeira é cada vez mais indispensável, o que tem despertado o interesse de pesquisadores e técnicos em todas as áreas vinculadas à atividade florestal no Brasil. É na perspectiva de tal fato que se desenvolveu a presente pesquisa, com o objetivo de realizar a caracterização energética de espécies de eucalipto para a produção de carvão vegetal, em comparação ao híbrido Eucalyptus grandis x Eucalyptus urophylla.

\section{MATERIAL E MÉTODOS}

O experimento foi realizado com cinco espécies do gênero Eucalyptus aos seis anos de idade. Após o corte e secagem em campo, foram selecionadas aleatoriamente três toras por material genético, totalizando 15 unidades. Adotou-se delineamento inteiramente casualizado com três repetições. Os tratamentos foram assim constituídos: T1 - Eucalyptus grandis Hill ex Maiden x Eucalyptus urophylla S. T. Blake, T2 - Eucalyptus propinqua H. Deane \& Maiden, T3 - Eucalyptus robusta Sm., T4 - Eucalyptus pellita F. Muell e T5 - Eucalyptus botryoides Sm.. A unidade experimental foi a tora, sendo que, de cada uma delas coletou-se discos com $5 \mathrm{~cm}$ de espessura, localizados à $0,25,50,75$ e $100 \%$ da altura comercial, cujo diâmetro mínimo foi de $5 \mathrm{~cm}$. Os discos foram transformados em cunha, que foram processadas e posteriormente moídas, formando uma amostra composta da tora.

O poder calorífico superior (PCS, $\mathrm{kcal} \mathrm{kg}^{-1}$ ) foi obtido em calorímetro, seguindo a norma da Associação Brasileira de Normas Técnicas 8633 (1984). O poder calorífico inferior, base seca, também foi estimado.

$\mathrm{Na}$ a determinação da densidade básica $\left(\mathrm{Db}, \mathrm{g} \mathrm{cm}^{-3}\right)$ da madeira foram seguidos os procedimentos recomendados pela norma M14/70 (ABTCP, 1968). A densidade energética (De, $\mathrm{kcal} \mathrm{m}^{-3}$ ) foi obtida conforme Equação 1.

$$
D e=D b . P C S
$$

em que: $D e$ é a densidade energética $\left(\mathrm{kcal} \mathrm{m}^{-3}\right) ; D b$ é a densidade básica $\left(\mathrm{g} \mathrm{cm}^{-3}\right)$; PCS é o poder calorífico superior $\left(\mathrm{kcal} \mathrm{kg}^{-1}\right)$.

Para se obter o carvão vegetal, as cunhas foram inseridas em estufa a temperatura de $103 \pm 2{ }^{\circ} \mathrm{C}$, até atingir massa constante. As carbonizações foram realizadas em forno elétrico (mufla) adaptado com controle de temperatura automático e incrementos de $0,5^{\circ} \mathrm{C} \cdot \mathrm{min}^{-1}$ até atingir temperatura máxima de $380{ }^{\circ} \mathrm{C}$ (temperatura inicial de $100^{\circ} \mathrm{C}$ ), permanecendo estabilizada por um período de 60 minutos. Procedeu-se com a recuperação do licor pirolenhoso, mediante condensação dos gases gerados no processo.

Após cada carbonização, foram determinados em relação à madeira anidra o rendimento gravimétrico em carvão (RGC, \%), em líquido pirolenhoso (RLP, \%), e em gases não condensáveis (RGNC, \%) por meio das Equações 2, 3 e 4 respectivamente.

$$
\begin{aligned}
& R G C_{\%}=(M c / M m) \cdot 100 \\
& R L P_{\%}=(M l / M m) \cdot 100 \\
& R G N C_{\%}=100-(R G C-R L P)
\end{aligned}
$$

em que: $R G C_{\%}$ é o rendimento gravimétrico de carvão $(\%) ; R L P_{\%}$ é o rendimento em líquido pirolenhoso (\%); $R G N C_{\%}$ é o rendimento em gases não condensáveis (\%); $M c$ é a massa do carvão (g); $M m$ é a massa seca da madeira (g); $M l$ é a massa do líquido pirolenhoso $(\mathrm{g})$. 
Foi realizada a análise imediata do carvão para determinar os teores de material volátil (MV, \%), de cinzas $(\mathrm{CZ}, \%)$ e de carbono fixo (CF, \%)), de acordo com os procedimento da norma NBR 8112 (ABNT, 1986).

Os dados foram submetidos aos testes de Lilliefors e de Cochran para avaliar a normalidade e homogeneidade de variâncias. Realizou-se a análise de variância, teste Tukey e análise de correlação linear segundo Pearson. Em todas as análises estatísticas adotaram-se 5,0\% de probabilidade e utilizou-se o programa SISVAR® (FERREIRA, 2000).

\section{RESULTADOS E DISCUSSÃO}

Todos os dados apresentaram normalidade e homogeneidade de variâncias. Na tabela 1 são apresentadas as médias de poder calorífico e densidades. Os baixos coeficientes de variação (menores que $10,0 \%$ ) evidenciaram a precisão experimental. É importante salientar que o PCS e o PCI variaram pouco dentro de um mesmo gênero, sendo que o uso do poder calorífico inferior é importante porque não inclui o calor latente da água presente nos produtos de combustão, ou seja, é a quantidade real de energia produzida pela combustão completa do material (em base seca).

Tabela 1. Médias de poder calorífico, densidade básica e densidade energética de espécies do gênero Eucalyptus aos seis anos de idade.

Table 1. Average values of calorific power, basic density and energy density of Eucalyptus species at six years old.

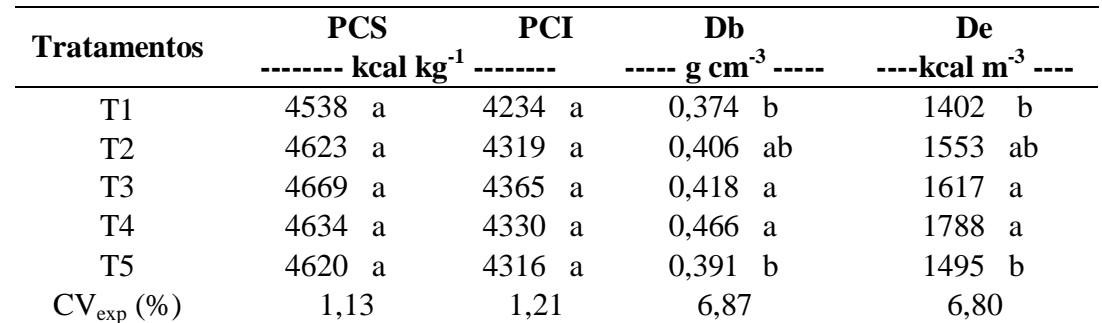

Legenda: PCS, poder calorífico superior; PCI, poder calorífico inferior; Db, densidade básica; De, densidade energética; $\mathrm{CV}_{\exp }=$ coeficiente de variação experimental. Médias seguidas pela mesma letra não se diferenciam pelo teste Tukey $(\mathrm{p}>0,05)$.

Estatisticamente, o poder calorífico do híbrido de Eucalyptus grandis x Eucalyptus urophylla foi semelhante às demais espécies de eucalipto (T2, T3, T4 e T5), assim a quantidade de energia térmica liberada pela oxidação dessas biomassas são similares. Valores encontrados nesse trabalho para o poder calorífico superior e inferior estão coerentes aos relatados na literatura para a madeira de Eucalyptus (BRAND et al., 2011; SANTOS et al., 2016; BRAND; MUÑIZ et al., 2010).

A densidade energética, que se relaciona à energia contida em um dado volume de madeira, foi maior nos tratamentos com o T2 e T3, portanto, superiores ao híbrido T1 (Tabela 1). Ocorreu a mesma tendência observada para a densidade básica da madeira. Os valores de Db destes materiais genéticos estão coerentes à faixa ideal para a produção de carvão vegetal, entre 0,4 a $1,2 \mathrm{~g} \mathrm{~cm}^{-3}$ (SILVA, 2001). Ressalta-se que é desejável uma madeira de elevada densidade básica, devido à maior massa do carvão vegetal produzido em um mesmo volume (NEVES et al., 2011).

As espécies de Eucalyptus foram estatisticamente semelhantes quanto aos rendimentos de carvão vegetal, observa-se também baixos coeficientes de variação amostral, o que sugere alta precisão das análises efetuadas, conforme apresentado na tabela 2. O rendimento médio em licor pirolenhoso (RLP) foi de 39,58\% já o rendimento médio em gases não condensáveis foi de $20,77 \%$, corroborando com outros trabalhos encontrados na literatura (SOARES et al., 2014; NEVES et al., 2011; ELYOUNSSI et al., 2010). Na literatura há diversos estudos (ARANTES et al., 2013; SOARES et al., 2014) com rendimento em carvão superior a 30\%, o que são valores desejados pelas indústrias, o que comprova o potencial das espécies T2, T3, T4 e T5, assim como o híbrido T1 para produção de carvão. Os rendimentos gravimétricos são sensivelmente influenciados tanto pela matéria prima quanto pelos parâmetros do processo como a temperatura e taxa de aquecimento. Segundo Elyounssi et al. (2010) e Vieira et al. (2013) o rendimento gravimétrico é sensivelmente influenciado por parâmetros de processo como a temperatura e quanto maior a temperatura final, menor o rendimento em massa, em razão do maior grau de volatilização da matéria orgânica, que resulta em menor rendimento em carvão vegetal e acréscimo nos rendimentos em líquido pirolenhoso. Sendo que a intensa degradação térmica não é interessante quando compromete a produção em rendimento do carvão.

FLORESTA, Curitiba, PR, v. 47, n. 1, p. 11 - 16, jan. / mar. 2017.

Jesus, M. S. de et al.

ISSN eletrônico 1982-4688

DOI: $10.5380 /$ rf.v47i1.48418 
Tabela 2. Médias de rendimento gravimétrico de carvão, rendimento em líquido pirolenhoso e rendimento em gases não condensáveis de espécies do gênero Eucalyptus aos seis anos de idade.

Table 2. Average values of gravimetric yield coal, pyroligneous liquid yield and non-condensable gases yield of Eucalyptus species at six years old.

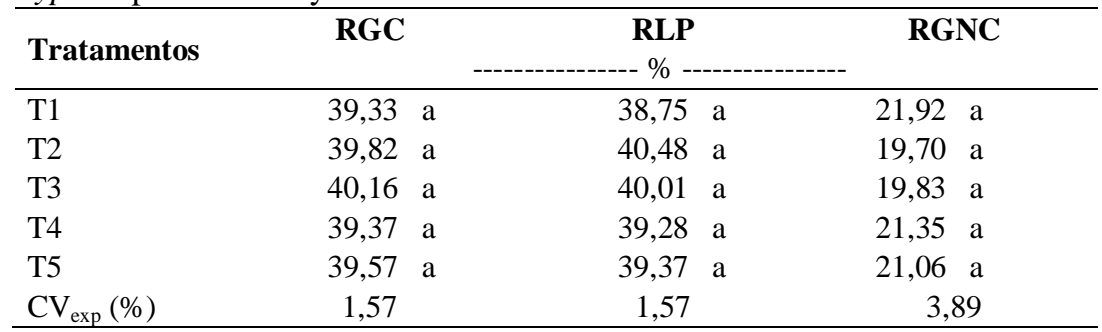

Legenda: RGC é o rendimento gravimétrico do carvão; RLP é o rendimento em licor pirolenhoso; RGNC é o rendimento em gases não condensáveis. $\mathrm{CV}_{\exp }$ é o coeficiente de variação experimental. Médias seguidas pela mesma letra não se diferenciam pelo teste Tukey $(\mathrm{p}>0,05)$.

Ao analisar o carvão vegetal produzido, foi observado conforme a tabela 3, que o T2 apresentou maior teor de materiais voláteis e menor teor em carbono fixo. O elevado teor de materiais voláteis não é desejável nas siderurgias, já que esse material compreende a parte do combustível que se evapora quando é aquecido a altas temperaturas e após a evaporação, misturam-se com o oxigênio do ar e entram em combustão, tornando-os mais instáveis termicamente.

Tabela 3. Médias dos teores de materiais voláteis, cinzas e carbono fixo de espécies do gênero Eucalyptus aos seis anos de idade.

Table 3. Average values of volatiles materials level, ashes level and fixed carbon level of Eucalyptus species at six years old.

\begin{tabular}{lrlrl}
\hline \multirow{2}{*}{ Tratamentos } & MV & CZ & CF \\
\hline T1 & 25,98 & $\mathrm{c}$ & $1,43 \mathrm{a}$ & $72,59 \mathrm{a}$ \\
$\mathrm{T} 2$ & $35,54 \mathrm{a}$ & $1,34 \mathrm{a}$ & $63,12 \mathrm{c}$ \\
$\mathrm{T} 3$ & $26,49 \mathrm{c}$ & $2,82 \mathrm{a}$ & $70,69 \mathrm{ab}$ \\
$\mathrm{T} 4$ & $29,60 \mathrm{~b}$ & $0,68 \mathrm{a}$ & $69,72 \mathrm{~b}$ \\
$\mathrm{~T} 5$ & $27,16 \mathrm{bc}$ & $2,25 \mathrm{a}$ & $70,58 \mathrm{ab}$ \\
$\mathrm{CV}_{\exp }(\%)$ & 1,90 & 2,24 & 0,79 \\
\hline
\end{tabular}

Legenda: MV é o material volátil; $\mathrm{CZ}$ é o teor de cinzas; $\mathrm{CF}$ é o teor de carbono fixo. $\mathrm{CV}_{\text {exp }}=$ coeficiente de variação experimental. Médias seguidas pela mesma letra não se diferenciam pelo teste Tukey $(\mathrm{p}>0,05)$.

Na tabela 3 pode-se observar que, embora a variabilidade na análise química imediata tenha sido baixa (média de 1,64 \%), o teor de cinzas apresentou maior coeficiente de variação. Segundo Souza et al. (2012), isso pode ser explicado em razão do menor valor numérico das cinzas em relação ao material volátil e carbono fixo. Observou-se que todos os materiais genéticos são estatisticamente iguais para o teor de cinzas. Segundo Santos (2016) para uso siderúrgico é indicado teores de cinzas no carvão inferior a 1\%, para evitar contaminação e redução do seu poder calorífico, uma vez que causa desgaste no alto-forno e pode comprometer a qualidade do ferro-gusa com consequentes formações de trincas e fissuras.

Os maiores teores de carbono fixo foram observados para o híbrido de T1, T3 e T5. A partir da premissa que o porcentual de carbono fixo refere-se à fração de carvão que se queima no estado sólido, combustíveis com teores elevados de carbono fixo são preferíveis para uso siderúrgico, devido à estabilidade térmica e elevado poder energético (NEVES et al., 2011).

$\mathrm{Na}$ tabela 4 estão apresentadas as correlações entre as variáveis estudadas. Considerou-se que duas variáveis possuem associação entre si quando o coeficiente de correlações foi significativo a 5,0 \% de probabilidade. A correlação da densidade básica em relação a densidade energética foi positiva $\left(r_{y \hat{y}}=1,0\right)$ e alta (maior que 0,8), ou seja, madeiras de maior densidade básica apresentaram maior densidade energética. Resultados estes que corroboram com as densidades observadas nos tratamentos que envolveram T2, T3 e T4 (Tabela 1). Assim, a densidade energética da madeira tende a aumentar linear e proporcionalmente a densidade básica, como observado nesse trabalho, dessa forma materiais mais densos tende a apresentar maior quantidade de energia disponível.

O teor de carbono fixo aumentou, para um mesmo rendimento gravimétrico, em espécies que apresentaram menor porcentagem de materiais voláteis. De acordo com Leite et al. (2015) o comportamento do 
teor de material volátil é oposto ao de carbono fixo, já que esse último parâmetro é obtido por diferença. Os resultados da análise química imediata não se correlacionaram com o poder calorífico e densidades.

Há também uma significativa correlação negativa entre o rendimento de carvão gravimétrico e o rendimento em gases não condensáveis e em licor pirolenhoso, o que já era esperado, pois quanto maior o grau de desvolatização da madeira, menor é o rendimento em carvão, principalmente quando não há favorecimento das reações secundárias (DI BLASI, 2008).

Tabela 4. Coeficientes de correlação linear entre as características energéticas de espécies do gênero Eucalyptus aos seis anos de idade.

Table 4. Linear correlation coefficients between the energy characteristics of Eucalyptus species at six years of age.

\begin{tabular}{lcccccccc}
\hline Variável & Db & De & RGC & RLP & RGNC & MV & CZ & CF \\
\hline PCS & 0,615 & 0,685 & 0,719 & 0,674 & $-0,724$ & 0,200 & 0,383 & $-0,305$ \\
PCI & 0,615 & 0,685 & 0,719 & 0,674 & $-0,724$ & 0,200 & 0,383 & $-0,305$ \\
PCU & 0,618 & 0,687 & 0,717 & 0,675 & $-0,724$ & 0,204 & 0,378 & $-0,309$ \\
Db & & $0,996^{*}$ & 0,016 & 0,180 & $-0,129$ & 0,239 & $-0,407$ & $-0,165$ \\
De & & & 0,099 & 0,243 & $-0,202$ & 0,240 & $-0,329$ & $-0,184$ \\
RGC & & & & 0,794 & $-0,907^{*}$ & 0,143 & 0,726 & $-0,322$ \\
RLP & & & & & $-0,976^{*}$ & 0,709 & 0,254 & $-0,826$ \\
RGNC & & & & & & $-0,542$ & $-0,436$ & 0,687 \\
MV & & & & & & & $-0,454$ & $-0,979^{*}$ \\
CZ & & & & & & & & 0,261 \\
\hline
\end{tabular}

Legenda: PCS é o poder calorífico superior; PCU é o poder calorífico útil; Db é a densidade básica; De é a densidade energética; RGC é o rendimento gravimétrico em carvão; RLP é o rendimento em líquido pirolenhoso; RGNC é o rendimento em gases não condensáveis; MV é o teor de material volátil; CZ é o teor de cinzas; CF é o teor de carbono fixo. ${ }^{*}(p<0,05)$.

O aproveitamento da biomassa florestal das espécies do gênero Eucalyptus, estudadas nesse trabalho para fins energéticos, é promissor. O Eucalyptus robusta apresentou características energéticas semelhantes ao híbrido de Eucalyptus grandis x Eucalyptus urophylla (PCS, PCI, RGC, RLP, RGNC, MV, CZ e CF) e, em alguns casos, superiores (Db e De). Salienta-se que a produção de biomassa pode gerar receitas que viabilizam economicamente seu aproveitamento em siderurgias. Além disso, sistemas de produção de biomassa energética são planejados e dimensionados visando concentrar a maior produção em função da área (MÜLLER et al., 2005).

Diante da atual demanda por novas espécies para utilização como biomassa biorredutora, os resultados deste trabalho podem ser utilizados como ponto de partida para pesquisas posteriores e auxílio no planejamento de programas de melhoramento genético e implantação de florestas energéticas.

Recomenda-se que mais pesquisas, sobre o potencial energético de espécies não utilizadas convencionalmente para a produção de carvão vegetal, sejam realizadas.

\section{CONCLUSÕES}

- As espécies Eucalyptus propínqua, Eucalyptus robusta, Eucalyptus pellita e Eucalyptus botryoides, assim como o híbrido Eucalyptus grandis x Eucalyptus urophylla, apresentam características potenciais (PCS, Db e De) paara a produção de carvão vegetal, com rendimento gravimétrico médio de 39,65\% (seguindo as condições experimentais desse trabalho).

- O Eucalyptus robusta é a espécie mais promissora para fins energéticos e para ser utilizado como biorredutor pelas indústrias siderúrgicas, devido suas caracaterística da madeira e do carvão vegetal.

\section{REFERÊNCIAS}

ARANTES, M. D. C.; TRUGILHO, P. F.; SILVA, J. R. M. da; ANDRADE, C. R. Características do carvão de um clone de Eucalyptus grandisW. Hill ex Maiden x Eucalyptus urophylla S. T. Blake. Revista Cerne, Lavras, v. 19, n. 3, p. 423-431, 2013.

ASSOCIAÇÃO BRASILEIRA DE NORMAS TÉCNICAS (ABNT). NBR 8112: Carvão vegetal: Análise química imediata. Rio de Janeiro: ABNT, 1986. 5 p.

ASSOCIAÇÃO BRASILEIRA DE NORMAS TÉCNICAS (ABNT). NBR 8633: Carvão vegetal: Determinação do poder calorífico. Rio de Janeiro: ABNT, 1984. 13 p.

FLORESTA, Curitiba, PR, v. 47, n. 1, p. 11 - 16, jan. / mar. 2017.

Jesus, M. S. de et al.

ISSN eletrônico 1982-4688

DOI: $10.5380 /$ rf.v47i1.48418 
ASSOCIAÇÃO BRASILEIRA TÉCNICA DE CELULOSE E PAPEL (ABTCP). M14/70: métodos de ensaio. São Paulo: ABTCP, 1974. p. 45-52.

BRAND, M. A.; MUÑIZ, G. I. B.; QUIRINO, W. F.; BRITO, J. O. Storage as a tool to improve wood fuel quality. Biomass and Bioenergy, Oxford, v. 35, p. 2581-2588, 2011.

BRAND, M. A.; MUÑIZ, G. B. I. Influência da época de colheita da biomassa florestal sob sua qualidade para a geração de energia. Scientia Forestalis, Piracicabe, v. 38, v. 88, p. 619-628, 2010.

COELHO, S. R. F.; GONÇALVES, J. L. M.; MELLO, S. L. M.; MOREIRA, R. M.; SILVA, E. V.; LACLAU, J. Crescimento, nutrição e fixação biológica de nitrogênio em plantios mistos de eucalipto e leguminosas arbóreas. Pesquisa Agropecuária Brasileira, v. 42, n. 6, p. 759-768, 2007.

DI BLASI, C. Modeling chemical and physical processes of wood and biomass pyrolysis. Progress in Energy and Combustion Science, Italy, v. 34, n. 1, p. 47-90, 2008.

ELYOUNSSI, K.; BLIN, J.; HALIM, M. High-yield charcoal production by two-step pyrolysis. Journal of Analytical and Applied Pyrolysis, Amsterdam, v. 87, n. 1, p. 138-143, Nov. 2010.

FERREIRA, D. F. Análise estatística por meio do SISVAR (Sistema para Análise de Variância) para Windows versão 4,0. In: REUNIÃO ANUAL DA REGIÃO BRASILEIRA DA SOCIEDADE INTERNACIONAL DE BIOMETRIA, 45, 2000, São Carlos, São Paulo. Anais... São Carlos: UFSCar, 2000. p. 255-258.

INDÚSTRIA BRASILEIRA DE ÁRVORES. Associação que representa os segmentos de painéis e pisos de madeira, celulose, papel e florestas energéticas. Brasília: IBÁ, 2015. 80 p.

LEITE, E. R. S.; PROTÁSIO, T. P.; ROSADO, S. C. S.; TRUGILHO, P. F.; MELO, I. C. N. A. M. Qualidade do carvão vegetal produzido a partir da madeira do cafeeiro, para uso bioenergético. Rev. Coffee Science, Lavras, v. 10, n. 2, p. 251-261, 2015.

LU, S.; LI, L.; YI, X.; JOSHI, C. P.; CHIANG, V. L. Differential expression of three eucalyptus secondary cell wall-related cellulose synthase genes in response to tension stress. Journal of Experimental Botany, v. 59, n. 3, p. 681-695, 2008.

MÜLLER, M. D.; COUTO, L.; NEVES, J. C. L. Produção de biomassa e balanço nutricional de plantações de eucalipto clonal em diferentes densidades de plantio no município de Itamarandiba-MG. Biomassa \& Energia, v. 2, n. 2, p. 91-101, 2005.

NEVES, T. A.; PROTÁSIO, T. P.; COUTO, A. M.; TRUGILHO, P. F.; SILVA, V. O.; VIEIRA, C. M. M. Avaliação de clones de Eucalyptus em diferentes locais visando à produção de carvão vegetal. Pesquisa Florestal Brasileira, v. 31, n. 38, p. 319-330, 2011.

OLIVEIRA, A. C.; CARNEIRO, A. C. O.; VITAL, B. R.; ALMEIDA, W.; PEREIRA, B. L. C.; CARDOSO, M. T. Parâmetros de qualidade da madeira e do carvão vegetal de Eucalyptus pellita F. Muell. Scientia Forestalis, v. 38, n. 87, p. 431-439, 2010.

SANTOS, R. C.; CARNEIRO, A. C. O.; VITAL, B. R.; CASTRO, R. V. O.; VIDAURRE, G. B.; TRUGILHO, P. F.; CASTRO, A. F. N. M. Influência das propriedades químicas e da relação siringil/guaiacil da madeira de eucalipto na produção de carvão vegetal. Revista Ciência Florestal, Santa Maria, v. 26, n. 2, p. 657-669, 2016.

SILVA, J. C. Caracterização da madeira de Eucalyptus grandis Hill ex. Maiden, de diferentes idades, visando a sua utilização na indústria moveleira. 2001, 160 f. Tese (Doutorado em Ciência Florestal) Universidade Federal do Paraná, Curitiba, 2001.

SOARES, V. C.; BIANCHI, M. L.; TRUGILHO, P. F.; JÚNIOR PEREIRA, A.; HÖFLER, J. Correlações entre as propriedades da madeira e do carvão vegetal de híbridos de eucalipto. Revista Árvore, Viçosa, v. 38, n. 3, p. 543-549, 2014.

SOUZA, M. M.; SILVA, D. A.; ROCHADELLI, R.; SANTOS, R. C. Estimativa poder calorífico e caracterização para uso energético de resíduos da colheita e do processamento de Pinus taeda. Revista Floresta, v. 42, n. 2, p. 325-334, 2012.

TRUGILHO, P. F.; LIMA, J. T.; MENDES, L. M. Influência da idade nas características físico-químicas e anatômicas da madeira de Eucalyptus saligna. Revista Cerne, Lavras, v. 2, n. 1, p. 1-15, 2009.

VIEIRA, R. S.; LIMA, J. T.; MONTEIRO, T. C.; SELVATTI, T. S.; BARAÚNA, E. E. P.; NAPOLI, A. Influência da temperatura no rendimento dos produtos da carbonização de Eucalyptus microcorys. Revista Cerne, Lavras, v. 19, n. 1, p. 59-64, set. 2013. 